\title{
Editorial - Volume 2 (2)
}

\section{Introduction}

Welcome to the fourth issue of Exchanges: the Warwick Research Journal. This issue completes the second volume of the journal and continues in promoting cross-disciplinary research through the publication of high quality articles. This issue includes articles from a range of disciplines including sociology, education, classics and ancient history, literature, history, film and nanoscience.

This issue coincides with the celebration of University of Warwick's 50th anniversary year 2015. The University of Warwick first opened its doors in 1965 , with the first intake of students to its campus in October that year. In its first 50 years, the University has undergone enormous change, with the continual development of buildings, courses and its international research profile.

To mark this important milestone, the University is hosting a number of events throughout the year, such as the 1965 intake reunion, the festival of the imagination and the Warwick music festival. The Institute of Advanced Study at the University of Warwick is making a significant contribution to mark the 50th anniversary through its oral history project, 'Voices of the University: Memories of Warwick, 1965-2015'. So far, over 200 hundred people who have studied and worked the University or lived nearby have shared their memories of the University charting its life over the last half century.

\section{Exchange, debate, and dialogue}

To make our contribution to the 50th anniversary celebrations, we have interviews with University of Warwick alumna and world-renown children's author, Anne Fine and University of Warwick's rising star, Dr Michael Scott, Associate Professor in Classics and Ancient History.

Philip Gaydon who's currently studying for a PhD in philosophy and literature at the University of Warwick takes the opportunity to discuss with Anne Fine her views on the role literature plays in the education of children. Fine talks candidly about her experience as Children's Laureate and her writing process where she discusses her motivations and inspirations.

Dr Ersin Hussein, who has recently completed her PhD in Classics and Ancient History at the University of Warwick, talks to Dr Michael Scott 
about his passion for ancient history and archaeology. In their conversation, they cover a number of topics such as the concept of space and the importance of interdisciplinarity to the field. They also discuss his numerous radio and TV series, such as his BBC Radio 4 documentary, Spin the Globe, where Michael Scott talks about how these projects came about.

\section{Featured section: Inequality in Teaching - Innovation in Methods}

Demonstrating the forward thinking approach that the University of Warwick fosters, two PhD students, Siobhan Dytham and Carli Ria Rowell organised a two-day conference (November 2014) with the support of the ERSC Doctoral Training Centre, which sought to bring together researchers who investigate alternative ways of researching inequality in education. The huge success of this event has been documented by bringing together a collection of articles that reflect the research presented at the event.

Opening this featured section, Inequality in Education - Innovation in Methods, Dytham and Rowell chart the background and development of the conference, and introduce the articles we have featured in this issue. Their introductory comments are followed by contributions from the two keynote speakers, Dr Nicola Ingram and Professor Melanie Nind, who discuss their own research in this field. The conference explored three main themes: innovative research methods, disability, and race and class. The articles featured in this special section, written by postgraduate students, represent each of these themes.

In Farhat Syyeda's article, 'A Picture is Worth a Thousand Words: Examining learners' illustrations to understand Attitudes towards Mathematics' she presents a case study, which explores the attitudes of secondary school children (ages 11 and 15 ) towards Mathematics. In promoting innovative research methods, she discusses her use of encouraging students to draw pictures as an alternative medium of communication to the standard verbal approach. Syyeda argues that this enables students greater opportunity to express themselves, which can provide greater insight into their emotional and cognitive responses to mathematics, helping us to better understand their attitudes.

On the theme of disability, Jacqui Shepherd in her article 'Interrupted Interviews': listening to young people with autism in transition to college', discusses innovative methods to improve access to important data on attitudes of students with autism to their move from secondary 
education to further education colleges. Her research project focused on the lived experiences of young people with autism as they made the transition from special schools to mainstream colleges of Further Education. Shepherd makes a convincing case that in conducting research in the sociology of education, it is essential to include visual and embodied methods for capturing the attitudes of participants, in this case, making use of photographs alongside tours with the participants.

With specific focus on the issue of class, Jessica Faye Heal in 'Research with School Students: Four Innovative Methods Used to Explore Effective Teaching' outlines four research methods to enhance how students from low-income backgrounds engage in research exploring effective teaching. These methods include semi-structured interviews, child-led classroom tours and a creative 'draw and tell' approach. Heal argues for the need to disrupt the researcher-participant power imbalance in order to successfully research certain groups of students.

We conclude the featured section with 'Reflections and considerations' from the two conference organisers, Siobhan Dytham and Carli Ria Rowell. In addition to drawing out dominant themes that emerged from the conference, they also discuss the possibilities that innovative methods offer in terms of including a wider range of participants in research and increasing opportunities for participants to be involved with the research process and communicate effectively. The article ends with some ethical considerations in relation to new and innovative research methods before drawing to a conclusion.

\section{Creativity in research and teaching}

Reflecting on the articles published in this issue, the central theme that unites all of the articles is creativity. An important aspect of both teaching and research. Creativity in teaching is an essential part of providing a good education, enabling students to think for themselves and develop crucial transferable skills. And, of course, creativity in research is essential in making those break-throughs; to make discoveries, we need to find a way of moving into new territory.

But how do we cultivate and develop such creativity? This is the question addressed by Monica Murgia's article, 'Teaching Synaesthesia as a Gateway to Creativity'. Here, she describes her innovative approach to teaching fashion by cultivating and developing students' creativity. By encouraging her students to investigate cross-modal responses to stimuli, this pushed the students beyond their default responses to consider the depth and breadth of possible response, which Murgia found led to greater creative output. Murgia also describes how this innovative 
approach to teaching has informed her own practice as an artist, showing the benefit for both student and teaching in research-led teaching.

\section{Innovative approaches at the University of Warwick}

In addition to our featured section on 'Inequality in Education, Innovation in Methods', this issue also includes two further reflections on innovative, interdisciplinary conferences that have recently taken place at the University of Warwick, economic historian Karolina Hutkova's 'The Global Trade of Textiles and Clothing in the Early Modern Period:

Exchange, Meaning and Materialities' and nano-scientists Robin and Davies' 'Emerging Nanomaterials for Healthcare'.

In Karolina Hutkova's article, she reflects on the event, 'The Global Trade of Textiles and Clothing in the Early Modern Period: Exchange, Meaning and Materialities', which took place November 2014 at the University of Warwick. This event brought together early career researchers investigating aspects of textile history, including production, consumption, trade, fashion, and design. Hutkova discuss the success of the event in drawing broader conclusions about the role of textiles and clothing in the development of societies, cultures and economies.

Robin and Davies, both research fellows at the Institute of Advanced study, reflect on their one-day conference "Emerging Nanomaterials for Healthcare", which was held at the University of Warwick on 28 November 2014. In this critical reflection, Davies and Robin provide an overview of the event which aimed to provide an interdisciplinary forum to discuss research towards solving current problems in healthcare using "smart" treatments based on nanomaterials. They reflect on evidence of successful applications of nanomaterials in providing solutions to issues in healthcare that emerged from the conference, as well as considering future directions for this important area of research.

Finally, in the article, 'Interrogating Practices of Gender, Religion and Nationalism in the Representation of Muslim Women in Bollywood: Contexts of Change, Sites of Continuity' by Sociology PhD students at the University of Warwick, Nazia Hussein and Saba Hussain, further demonstrates the excellent interdisciplinary and innovative work being undertaken at the university.

In this article, the authors analyse four recent Bollywood films to show the role Bollywood plays in the creation of hierarchical identities in the Indian society. The article focuses on the representation of Muslim heroines in these films. The authors argue that the nature of the recent 
deployment of Muslim heroines in Bollywood reinforce the hierarchy between genders, communities and nations.

\section{Thanks}

Many thanks for your continued support of the journal; our readers play an important part in the life of the journal. We hope you find this issue as stimulating as we have and that the connections that emerge, not just between the articles but also with your own research, will lead to exciting avenues for the future of our disciplines. We also remind you to join in the discussion with our new Disqus function, which allows you to share your thoughts or ask questions about the individual articles.

Finally, we want all of the peer reviewers who volunteered their time to read each of our submissions carefully and provide helpful, constructive comments for our authors. We also want to thank Yvonne Budden, Scholarly Communications Manager, University of Warwick Library, for her continued support and assistance with the development of the journal.

We look forward to the next issue, which is due to be published in October 2015 and will feature an interview with Professor Michael Levitt.

The Editors

Melina Dritsaki / Warwick Medical School

Ersin Hussein / Classics and Ancient History

Elisa Lopez-Lucia / Politics and International Studies

Misato Matsuoka / Politics and International Studies

Karen Simecek / Philosophy and Literature 